\title{
Research on the New Type of the Biological Suspended Filler
}

\author{
Jianyun HE ${ }^{\mathrm{a}}$, Weijia KANG , Chengshuo WANG, Chunxian YE, Hong HE ${ }^{\text {b,* }}$, Weimin \\ YANG and Yumei DING \\ ${ }^{1}$ Beijing University of Chemical Technology, Beijing China100029 \\ Yinglan Laboratory of Advanced Polymer Processing \\ ajyhe2009@163.com, ${ }^{\mathrm{b}}$ Hehong668@163.com
}

\begin{abstract}
At present, much research has been down to deal with urban sewage in the world to overcome the problem of urban water shortage. And many sewerage treatment systems need to be transformed to meet the requirement of city development. The method of using Bio-film to deal with urban sewage has gotten more attention by the countries of the world. Hydrophilic modified biological suspended filler is one of core technologies in the sewage treatment system which affects the efficiency, energy consuming, stability and reliability of the urban sewerage treatment. In this paper the new hydrophilic modified biological suspended filler is researched systematically and the processing technique is studied. The hydrophilic and mechanic performance of the suspended filler was tested. Results shown that the new type of hydrophilic modified suspended filler has good hydrophilic and meets the demand of urban sewage treatment system, which has great meaning and value in solving the problem of urban sewage and recycling.
\end{abstract}

Keywords: urban sewage treatment; biological suspended filler; hydrophilic modified; mechanics performance; contact angle

\section{Introduction}

Wastewater is the main water pollution sources. Improper handling will bring a series of ecological and environmental problems which influence and endanger the urban survival and development, pollute the water and soil, break water balance, deteriorate the water quality, and increase the water shortages and urban load [1-3].

The current level of the sewage treatment industry and technology in our country still lags behind the developed countries. The main problems faced include the imperfect sewage treatment materials and treating process, inadequate facilities, low sewage

*Corresponding author: Hehong668@163.com 
treatment rate. The main pollutants in urban wastewater include: organic pollutants, ammonia, nitrogen, phosphorus, etc. At present the main methods to dislodge the pollutants are generally biological methods. Among the many biological methods, the biofilm method of urban wastewater treatment has been highly valued and studied by the countries around the world [4-5].

Hydrophilic suspended filler is the microorganism's vector and the biofilm habitat sites, affecting microbial growth, reproduction, shedding and shape, which have the major impact on the efficiency and effectiveness of wastewater treatment [6-8].

Due to LDPE is cost low, processing simple and widely used in china, in this paper LDPE was used as the basic material of biological filler, through hydrophilic modification to meet thelthe demand of urban sewage treatment and the market requirements of high-performance biological suspended filler.

\section{Materials and Equipment}

\subsection{The raw materials}

LDPE 6100M, LDPE607 Bought from Beijing yanshan petrochemical company; Dicumyl peroxide (DCP) Bought from Changzhou nord chemical new material co., LTD LDPE-g-MAH , polymer antistatic agent Laboratory synthesis LDPE-g-GMA, polymer antistatic agent Laboratory synthesis

\subsection{Equipment}

1) Material universal testing machine: Universal testing machine, INSTRON 1185, Instron Corporation.

2) Video contact angle measuring instrument (OCA20), DATAPHGSICS colloid chemistry company

3) co-rotating twin screw extruder, $L / D=60: 1, \emptyset_{m}=40$, Nanjing Keya company;

4) single screw extruder, $\emptyset_{\mathrm{m}}=30$ Weifang east China plastic machinery co., LTD;

5) High-speed dispersion machine SDF - 400 , Sai lung machinery equipment co., LTD. (Chengdu)

\section{Preparation of Biological Suspended Filler}

\subsection{Preparation of LDPE grafted master batch}

Formula of grafted master batch is shown in table 1.

TABLE1 THE FOMULA OF THE LDPE GRAFTED MASTER BATCH

\begin{tabular}{cccc}
\hline code & LDPE6100M & DCP & additive \\
\hline $1 \#$ & 100 & 0.08 & $\begin{array}{c}2 \\
\text { (HDPE-g-MAH) }\end{array}$ \\
\hline $2 \#$ & 100 & 0.08 & $\begin{array}{c}2 \\
\text { (HDPE-g-GMA) }\end{array}$ \\
\hline
\end{tabular}


Using twin-screw extruder, the extruding, extruder temperature in each area is controlled from 125 to $185{ }^{\circ} \mathrm{C}$.

\subsection{The structure design of the biological suspended filler}

The 19 holes three thin-walled structure was used as biological suspended carrier which consists of the annular inner plate, annular middle plate, annular outer plate and the connecting rib plates. The annular plate, medium plate, outer plate is fixed to the porous discs by connecting steel plate. An annular outer plate is dentate and distribute on the outside evenly, which enlarge the surface area. Thus, it can increase the surface membrane quantity and improve the volume load of biochemical reactions; at the same time it also can increase the surface roughness and reduce the wear and impact modification. The structure of biological suspended carrier is shown in Figure 1:

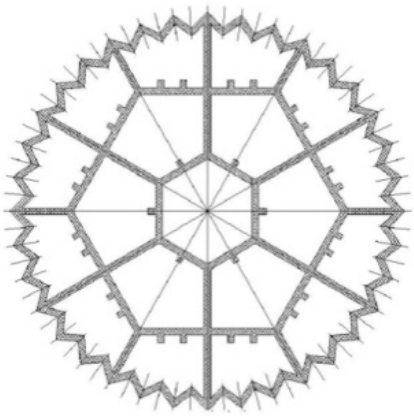

Figure 1

Using the bio-modified LDPE masterbatch and specialshaped mould during the extrusion of biological suspended filler, the contact angle of the material and the surface roughness of the filler can be increased, and the hydrophilic property of the filler was improved. It can also add nutrients in the filler to increase the activity of the filler and release more nutrient needed by the microbe, so that the filler can form biofilm faster with higher quality and possess greater water treatment ability.

Physical and chemical characteristics of the suspended filler depend on its material characteristics and the product properties after processing. Since the conversion of pollutants involves complex physical chemistry, biochemistry and energy transfer process which taken place in the bioreactor process, the reaction process is also involve in a complex pluralistic system. Therefore, the material of filler must have sufficient stability, including biological stability, chemical stability and thermal stability. Meanwhile it must be chemical inert, can bear temperature changes, and is not toxic to microbe and at the same time be with good surface charge characteristics and certain hydrophilic. In addition, based on biological oxidation process characteristics, suspended material density must be close to the density of water. The main parameters of size and characteristics of the suspended filler is shown in Table2 
TABLE2 THE MAIN PARAMETERS OF SIZE AND CHARACTERISTICS ON SUSPENDED

FILLER

\begin{tabular}{cccccc}
\hline $\mathrm{d} \times \mathrm{h} \times \mathrm{a}$ & density & specific surface & number of \\
$\mathrm{mm}$ & $\mathrm{g} / \mathrm{cm}^{3}$ & $\begin{array}{c}\text { area } \\
\mathrm{m}^{2} / \mathrm{m}^{3}\end{array}$ & $\begin{array}{c}\text { void } \\
\text { accumulation } \\
\text { volume } \\
\%\end{array}$ & $\begin{array}{c}\text { weight } \\
/ \mathrm{m}^{3}\end{array}$ & $\mathrm{~g}$ \\
\hline $25.0 \times 10.0 \times 0.4$ & 0.96 & 508 & 135256 & $>95$ & 0.8 \\
\hline
\end{tabular}

Filler surface wetting properties can be expressed by contact angle, surface tension and percentage of moisture. Contact angle and surface tension reflects the filler surface wetting properties, percentage of moisture reflects the hydrophilic property of the filler. The percentage of moisture is the weight ratio of the filler putted into water for a while to the filler before putted into the water. As for the other performance tests, the test sample was prepared by mixing LDPE6100M with modified master batch, then extruded by a single-screw extruder. The contact angle is measured on the video contact angle instrument. Then wetting tension was calculated; filler surface roughness and porosity are observed with an ordinary microscope; mechanical properties of biological filler were tested with electronic universal testing machine.

Through the test of the contact angle, the surface tension, the moisture content, the surface roughness and the porosity of biological filler, the suspended filler's formulation was optimized.

\section{The process of the biological filler}

The biological suspended filler with the hydrophilic property and biological affinity was prepared. The modify master batch was processed by the twin-screw extruder and the biological filler was produced by the single-screw extruder and the process technology was optimized.

Various performance was test on the hydrophilic modified biological suspended filler and compared with other two brands bio-filler obtained in the market.

\section{Results and Discussion}

\subsection{The water contact angle}

The surface contact angle of the hydrophilic modified suspended filler and the other two brands bio-filler was tested by video contact angle measuring instrument (OCA20), the test results was shown in Table 3.

TABLE3 THE SURFACE CONTACT ANGLE OF THE BIOLOGICAL FILLER

\begin{tabular}{ccc}
\hline code & left & right \\
\hline hydrophilic modified & 47.0 & 49.0 \\
suspended filler & & \\
Bio-filler1 & 83.9 & 84.1 \\
Bio-fille2 & 89.5 & 90.2 \\
\hline
\end{tabular}


The contact angle of both sample were low and $46.7 \%$ lower than other biological fillers. Results indicated that the wetting property of the bio-filler surface is good. Cesspool bio film test result shown that the growing speed of the bio-film on the filler surface and the bio-film's thickness is also good, which described that surface wettability of biological filler have a significant impact on the biofilm's attachment and growth property.

\subsection{Mechanical property}

Mechanical properties of the hydrophilic modified suspended filler and the other two brands bio-filler is tested on the electronic universal testing machine according to national standards GB / T1040, the test use type II and stretching rate is $50 \mathrm{~mm} / \mathrm{min}$. The mechanical properties results of biological affinity filler is shown in Table 4.

TABLE 4 MECHANICAL PROPERTIES OF BIOLOGICAL AFFINITY FILLER

\begin{tabular}{ccccc}
\hline sample & $\begin{array}{c}\text { tensile } \\
\text { strength } \\
\text { /Mpa }\end{array}$ & $\begin{array}{c}\text { fracture } \\
\text { stress } \\
/ \mathrm{Mpa}\end{array}$ & $\begin{array}{c}\text { fracture } \\
\text { extensibility } \\
/ \%\end{array}$ & $\begin{array}{c}\text { yield } \\
\text { intensity } \\
/ \mathrm{Mpa}\end{array}$ \\
\hline $\begin{array}{c}\text { hydrophilic } \\
\text { modified }\end{array}$ & 26.78 & 26.57 & 474.0 & 19.08 \\
$\begin{array}{c}\text { suspended filler } \\
\text { Bio-filler1 }\end{array}$ & 19.33 & 19.01 & 438.5 & 15.91 \\
Bio-fille2 & 17.12 & 15.65 & 348.4 & 15.28 \\
\hline
\end{tabular}

It can be seen from Table4, the tensile strength of the hydrophilic modified suspended filler is nearly $40 \%$ higher than that of the other two common biological filler, fracture extensibility and yield strength of common biological filler has also been greatly improved by the hydrophilic modified.

\subsection{Bio-film forming on the biological suspended filler}

The amount of microbe attached to the surface of the filler can reflect bio-film's performance which measured by the following method. Taking out a carrier with a certain amount of biofilm, put it into a $200 \mathrm{~mL}$ small beaker and wash it with deionized water several times, wash away suspended MLSS, and then put it in an oven at $105{ }^{\circ} \mathrm{C}$ drying, then cooling and weighing for $\mathrm{W} 1(\mathrm{~g})$. Then put the dried filler into the solution of $20 \%$ $\mathrm{NaOH}$, heated at $80^{\circ} \mathrm{C}$ for 1 h, the heating process accompanied by stirring until all the biofilm off, then pour out the liquid and wash with deionized water several times, then put it in the oven at $105^{\circ} \mathrm{C}$ drying, then cooling and weighing for $\mathrm{W} 2(\mathrm{~g})$. The amount of microbial on the surface of each filler can be calculated by the formula: X $=W 1-W 2$. By this way, the bio-film forming experiments of the modified filler was tested and compared with two other brand fillers under the same external experiment conditions, the results were shown in table5. 
Table 5 Biofilm forming experiment results of biological suspended filler

\begin{tabular}{cccc}
\hline \multicolumn{1}{c}{$\begin{array}{c}\text { hydrophilic } \\
\text { modified } \\
\text { sode }\end{array}$} & Bio-filler1 & Bio-filler2 \\
& filler & & \\
\hline Amount of microbe & 63.6 & 43.9 & 18.1 \\
\hline
\end{tabular}

It can be seen from Table5, the amount of microbe on the modified filler surface was more than that on the normal biological fillers, which illustrate that the modified filler is better in wastewater treatment.

\section{Conclusion}

In this paper the new hydrophilic modified biological suspended filler is researched systematically and the processing technique is studied. The hydrophilic and mechanic performance of the suspended filler was tested. Results shown that the new type of hydrophilic modified suspended filler has good hydrophilic and meets the demand of urban sewage treatment system. The hydrophilic modified suspended filler has great meaning and value in solving the problem of urban sewage and recycling.

At present, much research has been down to deal with urban sewage in the world to overcome the problem of urban water shortage. And many sewerage treatment systems need to be transformed to meet the requirement of city development. The method of using Bio-film to deal with urban sewage has gotten more attention by the countries of the world. Hydrophilic modified biological suspended filler is one of core technologies in the sewage treatment system which affects the efficiency, energy consuming, stability and reliability of the urban sewerage treatment.

The hydrophilic modified suspended filler has broad market prospects. A variety of new suspended fillers are born continuously. The development of suspended filler will be mainly focused on the two directions, one is to design more reasonable structure of the filler with more simple and more practical structure, and the other is to choose the right raw materials with reasonable surface characteristics. Thus it is important to develop the new type filler with the characters of large surface area, high mechanical strength and bio-film easy moving.

We will further improve the appearance and the treatment effect of the filler to make the filler structure more reasonable, more conducive for microbial hanging and reproduction.

Further research will be down on the structure, the chemical properties, the shedding mechanism and the activity of the biological filler to increase the surface area, reduce the cost of suspended filler and to promote microbial growth and reproduction.

\section{References}

1. Honhshu Chen. Current situation of water resources and water pollution control in China [J].Yunnan Environmental Science, 003, 22: 66-69.

2. Xiaochang Wang, PengkangJin, Hongmei Zhao. Evaluate of Classification and treatment of pollutants in urban domestic sewage [J]. Water supply and drainage, 2004, 30(9): 38-41. 
3. Yan An, Jiang Cheng. Effects of magnetic polyethylene fillers on the aerobic biodegradation of phenol wastewater[J]. China pulp and paper, 2007, 27(7): 19-22.

4. Jiang Cheng, Fan Zhang. The influence of the modification of hydrophilic and hydrophilic magnetic properties on the wettability and the performance of the film of polypropylene[J]. Journal of Chemical Indust, 2004, 55(9): 1564-1567.

5. YaminLiu ,Haibo Cui, ZhuoliHao. Research progress of application of fillers in biological treatment of wastewater [J]. Chemical engineering and equipment, 2008, 11: 115-116、 71.

6. Shefeng Liu. Study on the structure and performance of a novel mobile bed biofilm reactor B-CELL [D]. Jiang Nan University, 2000.

7. SheliCai, JingCai, ZunyuanRui. Mobile bed biofilm reactor and its application [J]. Shanghai Environmental Science, 2004, 23(6): 257-261.

8. SiqingXia. Pilot study on the removal of organic pollutants and ammonia nitrogen by suspended packing bioreactor [J]. Water supply and drainage, 2000, 126(12): 42-45. 